\title{
Urban drought
}

\author{
Wiwiana Szalińska ${ }^{1, *}$, Irena Otop ${ }^{1}$, and Tamara Tokarczyk $^{1}$ \\ ${ }^{1}$ Institute of Meteorology and Water Management - National Research Institute, 61 Podleśna Street, \\ 01-673 Warsaw
}

\begin{abstract}
Drought is recognized as one of the most complex natural hazards that have a large negative impact on society, economic sectors and the environment. Drought events affect freshwater resources and can become a great threat to urban water supply systems. According to climate change projections with an increase of air temperature and duration of dry periods, cities may experience a serious water shortage in the future that can limit sustainable urban development. Water-related consequences in urban areas can concern various socio-economic sectors as well as urban ecosystems. This paper focuses on drought in urban areas as an event of below-average natural water availability that can result in difficulties in meeting the water needs of socio-economic sectors and ecosystems particularly vulnerable to drought. Drought vulnerable sectors were identified within the local context of the City of Wroclaw area. Long-term analyses of meteorological and hydrological indicators were performed in order to estimate the drought hazard in Wrockaw. A combination of water shortage hazard and the vulnerability of water users were the basis to assess local drought risks. Reducing the drought risk requires coherent actions from both city and water managers. The paper presents a set of recommendable measures to avoid potential water shortages and to cope with impacts of drought in the Wroclaw area.
\end{abstract}

\section{Introduction}

The agglomeration of people, assets and economic activity make cities particularly vulnerable to natural hazards. An increase of both a city's population and urban areas results in an increased demand for products and services with greater water footprints. Observed and projected changes in a climate are likely to impact water resources [1]. The sustainable growth of cities depends on reliable water supply systems that are able to meet water demands and are robust enough to cope with drought [2]. Drought is defined as a sustained and regionally extensive occurrence of below average natural water availability [3] resulting from a range of phenomena which starts from precipitation deficit propagating over time and affecting the successive components of a hydrological cycle [4]. A lack of precipitation which lasts for a longer period of time can lead to the first phase of drought meteorological drought. A further shortage of precipitation leads to water deficit which causes soil drought and finally groundwater recharge reduction evolves into a hydrological drought. This phase causes a decrease in groundwater heads, groundwater discharges as

\footnotetext{
*Corresponding author: Wiwiana.Szalinska@imgw.pl
} 
well as streamflow decline $[5,6]$. The impacts of a drought differ between different city sectors and the drought phase. Drought formation is usually associated with high air temperature, low relative humidity and greater sunshine. In combination with excessive heating driven by urban development, drought periods can intensify and promote the formation of unfavourable urban climates that become a threat for human health and services for urban dwellers. Drought persistence is likely to alter water availability and trigger water resources scarcity. In cities the scarcity of water resources can also be associated with poor water management caused by the systematic growth of impervious area that increases the surface runoff and reduces water storage in soils. Droughts in urban areas represent situations that require action from water managers to avoid a potential water shortage or to manage the current one [2]. For effective drought management it is advocated to apply a risk approach based on drought hazard estimation and drought consequences in order to identify and apply measures to counteract drought and drought related consequences through preparation, response/recovery and adaptation planning. Drought mitigation relies on an effective water management system with special emphasis on rainwater collection, storage and treatment. To mitigate the impacts of drought related thermal factors (heat waves) it is tactical to ensure a sustainable city design that guarantees a percentage of surface that is permeable and biologically active, and protect ecological corridors and secure aeration wedges airing and cooling the city.

The purpose of this study is to assess the risks associated with drought formation, evolution and persistence in the city of Wrocław for the urban population, environment and economy sectors based on a multi-risk approach. An analysis of long-term meteorological and hydrological parameters was performed in order to estimate drought hazards. The main socio-economic sectors and urban ecosystems were examined in terms of their vulnerabilities to drought and drought related hazard. Estimated risk levels were used to identify a set of measures to avoid a potential water shortage and cope with the impacts of drought including educational, organizational and technical solutions.

\section{Materials and methods}

\subsection{Study Area and Database}

Wrocław is located in the south-west part of Poland. With an area of $293 \mathrm{~km}^{2}$ and a population close to 640000 inhabitants (in 2017 according to the Statistical Office in Wroclaw) it is one of the largest Polish cities. The geographical location of Wrocław in the temperate climate zone with oceanic and continental influences causes a large variability of weather conditions. The city area is cut by the Oder River and its tributaries and an extensive system of drainage and irrigation ditches.

A primary water source for Wrocław comes from surface water. Resources are secured by two retention and flood prevention reservoirs on the Nysa Kłodzka River (an Oder tributary): the Nysa reservoir and the Otmuchów reservoir. The size of the Nysa reservoir covers the entire current-use requirement of the Wrocław water company (24.15 million $\mathrm{m}^{3}$ ) with a 92-day reserve. Surface water from the Oława River is the direct resource for one of water treatment plants in Wrocław. Some water is taken to irrigate the 1026 ha water bearing area along the left bank of the Oława, where it undergoes natural ground filtration and is the infiltration water source for the second water treatment plant.

Analyses of drought and drought related conditions were carried out on the basis of measurements from the meteorological station Wrocław-Strachowice and 5 water gauge stations operated by the Institute of Meteorology and Water Management-National 
Research Institute (IMGW-PIB). Climatological and hydrological investigations were based on daily data recorded within the period of 1981-2015.

\subsection{Identification of key urban components}

Many city components are likely to suffer from drought and drought related hazards. The vulnerability of a particular city component is a measure of consequences of the analysed natural hazard for this component and the ability to cope with its impacts. Social, economic and environmental sectors of the city of Wroclaw were analysed in terms of their individual vulnerabilities to different drought phases. A set of key urban components were identified while analysing the city master plans, strategies, regulations and policies as well as consequences of historical drought events together with press and literature reports. The drought and drought related consequences for the respective city components are summarised below.

High air temperatures, together with intense solar radiation, cause strong human thermal stress, overloading the cardiovascular system, respiratory system and disorders of the body's thermal management. In the case of prolonged heat waves, mortality associated with cardiovascular and respiratory diseases increases, and the number of accidents on roads and in the workplace rises as well $[7,8,9,10]$. These effects are particularly felt by people living in the central districts of the city (due to building density, the high proportion of impermeable surfaces, poor ventilation and the urban heat islands effect). Rainless periods cause an increase in the concentration of allergens and dustiness in the air and lead to worsening symptoms of allergies and respiratory diseases. The most vulnerable group are small children, the elderly people and chronically ill persons.

Increases in air temperature are likely to raise the energy demand caused by air conditioning. It may reduce the efficiency of power production from fossil fuels, biofuels, hydropower and some solar power systems as they often require sustainable supplies of water for cooling. Issues related to restrictions on the temperature of cooling water returned to water bodies, also pose challenges to production from power plants.

Drought conditions are likely to impact the city water supply system by affecting the quality and quantity of the raw material introduced into the system. High temperatures increase the amount of bacteria in the network and reservoirs, causing the need to intensify water disinfection methods. Long-lasting dry periods, lead to increased water demand, including the irrigation of home gardens, and pose a threat related to the reduction of water pressure in taps in peripheral housing estates. In sewage and wastewater management, high temperature contributes to the increase of odor nuisance at sewage management facilities.

In the case of road and public urban transport, high temperatures may contribute to the increase of the susceptibility of bituminous surfaces to the impact of vehicles and, consequently, the need to limit the movement of heavy vehicles. There is a risk of overheating of vehicle engines and other technical devices. Heat waves reduce the comfort of journeys. In the rail subsystem, high temperatures may additionally cause overheating of railways and rail infrastructure causing speed limits as well as interruptions in power supply in traction due to possible overloading of power grids.

Low flows and hydrological droughts are a big threat to industry as the availability of water is crucial for many technological and cooling processes. Water scarcity can limit industrial production including crucial branches for Wroclaw: the electrotechnical industry, the car industry, the pharmaceutical industry, the biotechnology industry and the food industry. Low flows and hydrological droughts also limit open water related recreational activities like sailing, fishing, swimming. Drought impacts the city's green areas with the increased water stress and endangers water sensitive plants and animal species. 


\subsection{Drought and related hazard assessment}

Drought and drought related hazard assessments were done with the use of a set of indices and indicators based on meteorological and hydrological variables. Drought is usually categorized by the magnitude of deviation from normal conditions. Over the years, various researchers have proposed different indices to identify onset and characterize and quantify the attributes of different drought phases [i. e. 11, 12, 13, 14, 15].

The selection of the employed set of indices and indicators was done with reference to the identified key city components vulnerable to different drought phases. The following indices were applied to describe extreme events for the city of Wrocław: Extreme hot days (EHD) - defines days with the daily maximum temperature higher than the $98^{\text {th }}$ percentile of long term observations; Heat waves $(H W)$ - periods of at least three consecutive days with daily maximum air temperature higher than $30^{\circ} \mathrm{C}[16]$; Cooling degree days $(C D D)-$ represents the accumulated deviation of the air temperature over the days with the temperature exceeding the assumed threshold value, i.e. $27^{\circ} \mathrm{C}$ to provide information on the local cooling energy demand [17]; Long lasting dry spells (LLDS) - defines a series of consecutive days without precipitation or with daily totals $\leq 1 \mathrm{~mm}$ lasting more than 10 days; Low flow index - represents the period of the river flows below the assumed threshold value [19, 3, 20]; Standardized Precipitation Index (SPI) [13] is a standardized value of the totals of precipitation in a given time interval, and was used to identify periods of meteorological drought (MD); Standardized Runoff Index (SRI) - a standardized value of the runoff value and was used as an indicator of hydrological drought (HD) [18].

\subsection{Multi-risk assessment}

To assess the risks related to droughts and its derivative hazards, a multi-risk approach was used. This approach considers both hazard and vulnerability interactions in order to present a cause-effect matrix of hazard probability and vulnerability correlations. In the study, a semi-quantitative analysis was performed to obtain a 5-level classification of the hazard and vulnerability assessment individually. The hazard probability classification was based on the analysis of a long-term series presenting variability and trends in patterns of each of the adopted set of indices and indicators. A trend analysis was supported with investigations of the projected climate changes from regional climate models according to the RCP 4.5 and RCP 8.5 concentration pathways for the 2050 time horizon. The classification assigns the probability of a hazardous event occurrence (P): low (1), occasional (2), medium (3), high (4), very high (5). Vulnerability classification was done with reference to the observed and potential consequences of the analysed hazards for the particular city component. Respective categories of vulnerability described impacts in terms of time and resources required to return to normal conditions and the size of losses: negligible (1), marginal (2), serious (3), critical (4), catastrophic (5). A combination of this information indicated respective risk levels: low (L), medium $(\mathrm{M})$, high $(\mathrm{H})$, very high $(\mathrm{V})$.

\section{Results}

\subsection{Drought hazards estimation}

Drought and drought related phenomena hazards were estimated on the basis of the observed variabilities of the respective indices within the period 1981-2015 as well as projected climate change scenarios. Due to the observed and projected increase of air temperature, the highest probability of event occurrence was attributed to the extreme hot 
days, the cooling degree days as well as heat waves. The probabilities of occurrence of long lasting dry spells, dry spells with a high temperature and meteorological drought as their consequence were estimated as a high. Low flows and hydrological droughts were assessed on the level of medium probability of occurrence (Tab. 1).

Table 1. Drought and related hazards assessment.

\begin{tabular}{|c|c|c|c|}
\hline hazards & $\begin{array}{c}\text { observed frequency } \\
\text { and trend }\end{array}$ & climate change projections & $\boldsymbol{P}$ \\
\hline$E H D$ & $\begin{array}{c}\text { several times a year; } \\
\text { rising }\end{array}$ & $\begin{array}{c}\text { intensity may become critical over the } \\
\text { next few years }\end{array}$ & $\mathbf{5}$ \\
\hline$C D D$ & $\begin{array}{c}\text { over a dozen days a } \\
\text { year; rising }\end{array}$ & $\begin{array}{c}\text { intensity may become critical over the } \\
\text { next few years }\end{array}$ & $\mathbf{5}$ \\
\hline$H V$ & $\begin{array}{c}\text { several times a year; } \\
\text { rising }\end{array}$ & $\begin{array}{c}\text { intensity or frequency may become } \\
\text { critical over the next few years }\end{array}$ & $\mathbf{5}$ \\
\hline$L L D S$ & once a year; rising & $\begin{array}{c}\text { intensity may become critical over the } \\
\text { next ten years }\end{array}$ & $\mathbf{4}$ \\
\hline$L F$ & $\begin{array}{c}\text { every 4-8 years; no } \\
\text { trend }\end{array}$ & $\begin{array}{c}\text { intensity or frequency may become } \\
\text { critical over the next decades }\end{array}$ & $\mathbf{3}$ \\
\hline$M D$ & $\begin{array}{c}\text { every 2-3 years; no } \\
\text { trend }\end{array}$ & $\begin{array}{c}\text { intensity or frequency may become } \\
\text { critical over the next ten years }\end{array}$ & $\mathbf{4}$ \\
\hline$H D$ & $\begin{array}{c}\text { every 4-8 years; no } \\
\text { trend }\end{array}$ & $\begin{array}{c}\text { intensity or frequency may become } \\
\text { critical over the next decades }\end{array}$ & $\mathbf{3}$ \\
\hline
\end{tabular}

\subsection{Vulnerabilities of city components}

Vulnerability represents the propensity or predisposition of a community, system, or asset to be adversely affected by a certain hazard. City key component vulnerabilities were quantified according to the adopted vulnerability scale while analysing reported in different mass media losses and consequences, expert judgments of the City Council members and stakeholders representing different city sectors. In the City of Wroclaw the highest vulnerability values due to drought and drought related hazards were assigned to water supply, energy, industry, transportation, green areas, and a sensitive population (Fig. 1).

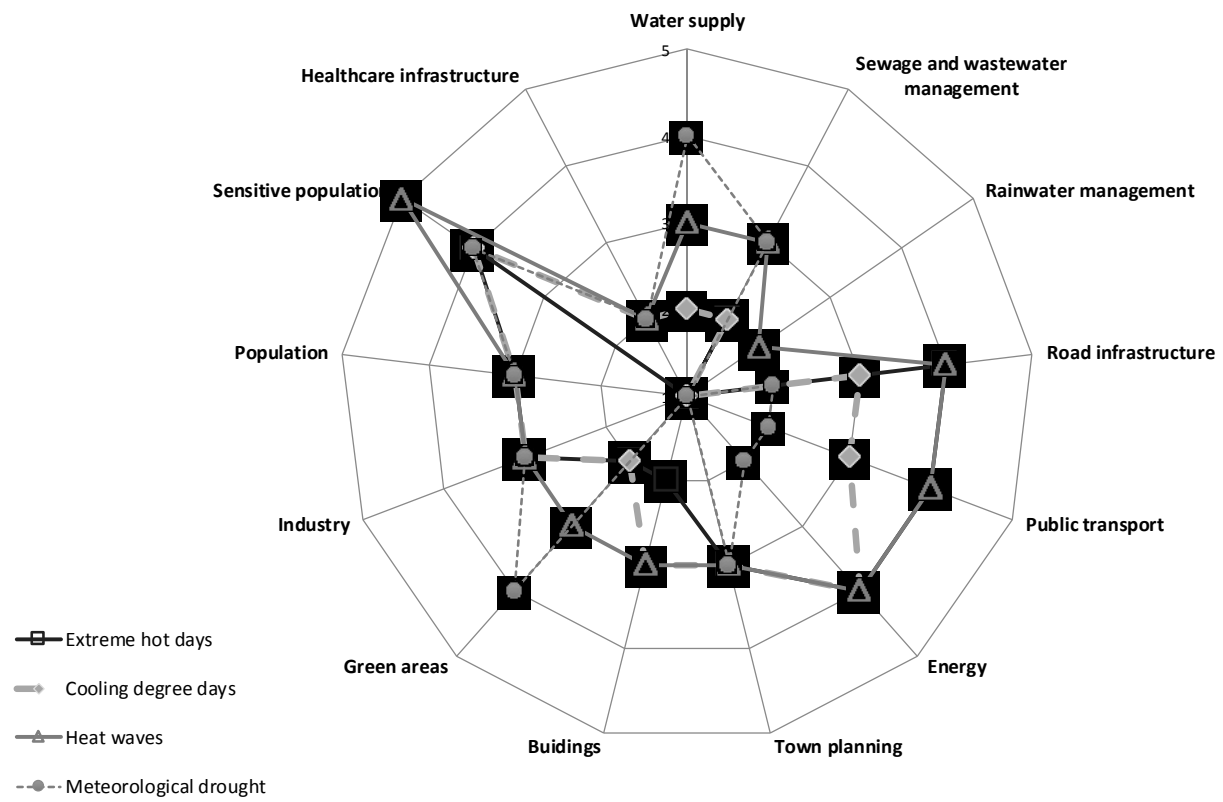




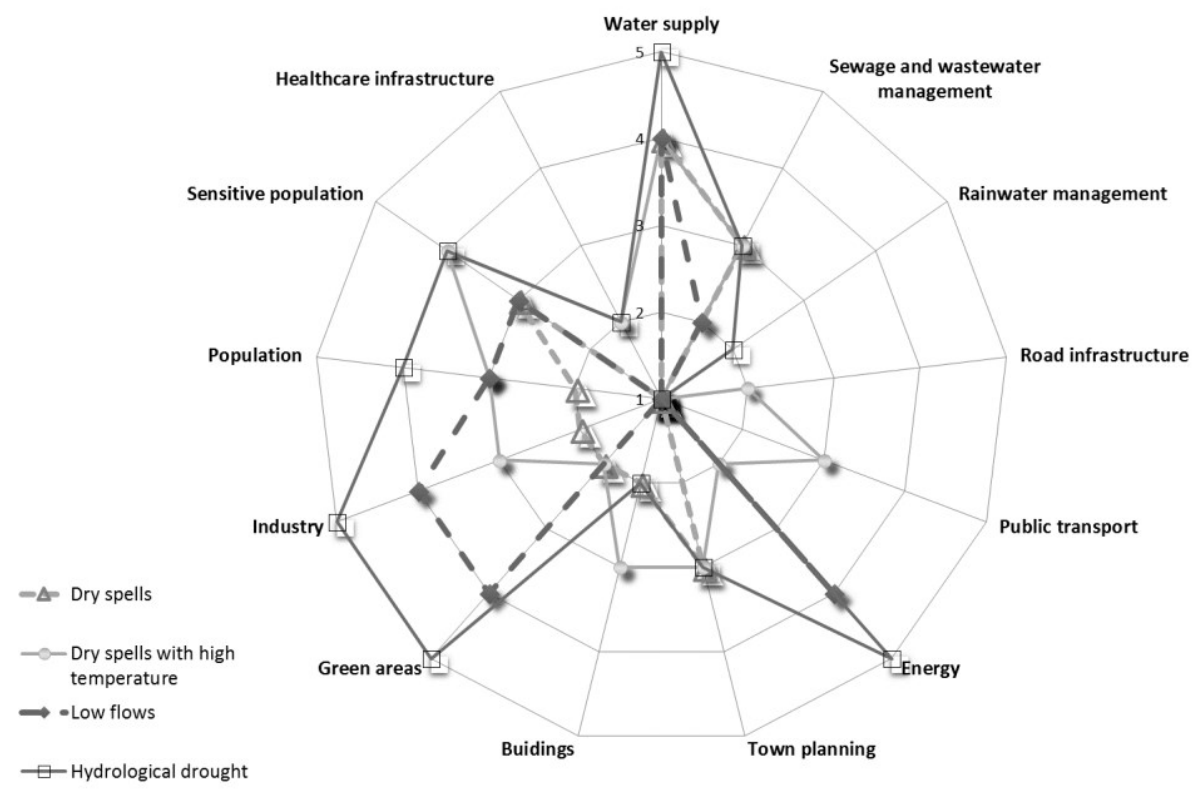

Fig. 1. Estimated vulerability levels for the analysed city components for extreme hot days, cooling degree days, heat waves and meteorological drought the hazards (upperm panel) and for long term dry spells, dry spells with a high temperature, low flows and hydrological drought hazards (lower panel).

\subsection{Drought risk assessment and mitigation measures}

The resulting matrix presents the main hotspots that require appropriate measures to mitigate the effect of drought and drought related phenomena in the City of Wroclaw area (Table 2). The highest risk values were attributed to the events of a very high probability of occurrence and catastrophic or critical consequences i.e. the impact of high temperatures on a sensitive population, energy and transport. High risks due to hydrological drought were found for water supply, energy and industry as well as for green areas. Risk levels correspond to the need to undertake the appropriate actions to mitigate potential drought consequences.

Table 2. Risk assessment matrix.

\begin{tabular}{|c|c|c|c|c|c|c|c|}
\hline City component & 胥 & $\hat{\mathrm{\theta}}$ & 主 & 今 & $\stackrel{\rho}{\Sigma}$ & 岃 & 主 \\
\hline Water supply & $\mathrm{M}$ & $\mathrm{H}$ & $\mathrm{H}$ & $\mathrm{H}$ & $\mathrm{H}$ & M & $\mathrm{H}$ \\
\hline Sewage and wastewater management & $\mathrm{H}$ & $\mathrm{H}$ & $\mathrm{H}$ & $\mathrm{H}$ & $\mathrm{H}$ & M & $\mathrm{M}$ \\
\hline Rainwater management & M & M & $\mathrm{H}$ & $\mathrm{M}$ & M & $\mathrm{L}$ & M \\
\hline Road infrastructure & $\mathrm{V}$ & $\mathrm{H}$ & V & M & M & $\mathrm{L}$ & $\mathrm{L}$ \\
\hline Public transport & $\mathrm{V}$ & $\mathrm{H}$ & V & M & M & $\mathrm{L}$ & $\mathrm{L}$ \\
\hline Energy & $\mathrm{V}$ & $\mathrm{V}$ & V & M & M & M & $\mathrm{H}$ \\
\hline Town planning & $\mathrm{H}$ & $\mathrm{H}$ & $\mathrm{H}$ & $\mathrm{H}$ & $\mathrm{H}$ & $\mathrm{L}$ & M \\
\hline Buidings & $\mathrm{H}$ & $\mathrm{H}$ & $\mathrm{H}$ & $\mathrm{M}$ & $\mathrm{H}$ & $\mathrm{L}$ & $\mathrm{M}$ \\
\hline
\end{tabular}




\begin{tabular}{|c|c|c|c|c|c|c|c|}
\hline Green areas & $\mathrm{H}$ & $\mathrm{H}$ & $\mathrm{H}$ & $\mathrm{M}$ & $\mathrm{H}$ & $\mathrm{M}$ & $\mathrm{H}$ \\
\hline Industry & $\mathrm{H}$ & $\mathrm{H}$ & $\mathrm{H}$ & $\mathrm{M}$ & $\mathrm{H}$ & $\mathrm{M}$ & $\mathrm{H}$ \\
\hline Population & $\mathrm{H}$ & $\mathrm{H}$ & $\mathrm{H}$ & $\mathrm{M}$ & $\mathrm{H}$ & $\mathrm{M}$ & $\mathrm{M}$ \\
\hline Sensitive population & $\mathrm{V}$ & $\mathrm{V}$ & $\mathrm{V}$ & $\mathrm{M}$ & $\mathrm{H}$ & $\mathrm{M}$ & $\mathrm{M}$ \\
\hline Healthcare infrastructure & $\mathrm{M}$ & $\mathrm{H}$ & $\mathrm{H}$ & $\mathrm{M}$ & $\mathrm{M}$ & $\mathrm{L}$ & $\mathrm{M}$ \\
\hline
\end{tabular}

An analysis of the resulting matrix indicated that for the City of Wroclaw area it is recommendable to develop and implement measures supportive to water management and town planning that concentrates on: i) development of the system of information on drought and related phenomena hazards, ii) improve outdoor human thermal comfort in city area, iii) managing energy system reliability and peak demand, iv) upgrading water supply safety and v) development of a system of green-blue infrastructure.

\section{Discussion}

According to the high impact scenario, most European cities will suffer from the increase of both drought and river flood risks. Guerreiro et al. [21] revealed an increase in the number of days and heat wave duration and the maximum heat wave temperature for all 571 analysed European cities with the highest increase for the cities of Central Europe. In Poland observed and projected future climate change, are mainly expressed in a significant increase in air temperature and changes in the structure of precipitation [22, 23]. Projections of SPI values for Poland indicate a decrease of dryness intensity during the winter months and an increase in the summer period within the $21^{\text {st }}$ century [24]. These factors may have an explicate effect on water resources while even now the availability of surface water resources is relatively low. At the same time, surface water resources are one of the main water supply sources for many urban areas. Therefore changes in climate may have a range of interrelated short- and long-term consequences for cities (i.e. human health, economic activities, social systems), depending on city preparedness and resilience. Climate changes may also affect cities indirectly by reduced agricultural production and disturbed food security as well as a reduced snowpack accumulation limiting river network reinforcement [25]. The recommended method for drought mitigation is an approach based on risk management $[26,27,2]$. According to this approach, the applied measures focus on supressing the probability of hazard occurrence and reducing its consequences. It can be achieved through a systematic approach comprising sustainable urban planning and water management [28]. For the City of Wroclaw the most vital activities included measures to protect the sensitive population against high temperatures, improve urban water budget, and ensure water and energy supply during peak demands.

\section{References}

1. R.K. Pachauri, L.A. Meyer (eds.), Climate change 2014: synthesis report. Contribution of working groups I, II and III to the fifth assessment report of the intergovernmental panel on climate change (Geneva, Switzerland, 2014)

2. J. Buurman, M.J.P Mens, R.J. Dahm, Int. J. Water Resour. D., 33, 31-50 (2017)

3. L.M. Tallaksen, H.A.J. van Lanen (eds.), Hydrological Drought - Processes and Estimation Methods for Streamflow and Groundwater (Developments in Water Science, 48, Elsevier Science, 2004) 
4. D.A. Wilhite (2000), Drought as a natural hazard: concepts and definitions, In: Drought: A global assessment, (Routledge Publishers, 2000)

5. K. Dębski, Hydrologia, (Arkady, 1970)

6. S.A. Changnon, Detecting drought conditions in Illinois (Illinois State Water Survey, ISWS/CIR-169/87, Champaign, USA, 1987)

7. T. Kozłowska-Szczęsna, B. Krawczyk, M. Kuchcik, Wpływ środowiska atmosferycznego na zdrowie i samopoczucie czlowieka (Monografie IGiPZ PAN, 2004)

8. K. Błażejczyk, M. Kuchcik, P. Milewski, W. Dudek, B. Kręcisz, A. Błażejczyk, J. Szmyd, B. Degórska, C. Pałczyński, Miejska wyspa ciepła w Warszawie: uwarunkowania klimatyczne i urbanistyczne (IGiPZ PAN, Wyd. Sedno, 2014)

9. M. Kuchcik, Geogr Pol, 86, 4, 295-311 (2013)

10. G.R. McGregor, M. Pelling, T. Wolf, S.N. Gosling, The Social Impacts of Heat Waves (Environment Agency UK, 2006)

11. W.C. Palmer, Meteorological drought (Weather Bureau, Washington, 1965)

12. T.B. McKee, N.J. Doesjen, J. Kelist, The relationship of drought frequency and duration to time scales. In: 8th AMS conference on applied climatology (AMS, 1993)

13. H-R. Byun, D.A. Wilhite, J Climate 12 (2), 747-756 (1999)

14. G. Tsakiris, Practical application of risk and hazard concept in proactive planning (European Water, 19/20. E.W. Williams Publications, 2007)

15. I. Nalbantis, G. Tsakiris, Water Resour Manag 23, 881-897 (2009)

16. U. Kossowska-Cezak, Pr. Geogr. IGiZP UJ, 123, 143-149 (2010)

17. M. Christenson, H. Manz, D. Gyalistras, Energy Convers Manage 47, 671-686 (2006)

18. S. Shukla, A.W. Wood, Geophys Res Lett., 35, 7 (2008)

19. M. Ozga-Zielińska, J. Brzeziński, Hydrologia stosowana (PWN, 1997)

20. T. Tokarczyk, Acta Geophys, 61, 404-421, (2013)

21. S. B. Guerreiro, R. J. Dawson, Ch. Kilsby, E. Lewis, A. Ford, Environ. Res. Lett. 13, 10 (2018)

22. M. Marosz, R. Wójcik, D. Biernacik, E. Jakusik, M. Pilarski, M. Owczarek, M. Miętus, Pr. i St. Geogr., 47, 51-66 (2011)

23. Z. Kundzewicz, O. Hov, T. Okruszko (eds.), Zmiany klimatu i ich wplyw na wybrane sektory w Polsce (Poznań, 2017)

24. M. Osuch, R. J. Romanowicz, D. Lawrence, W.K. Wong, Hydrol. Earth Syst. Sci., 20, 1947-1969 (2016)

25. Guide to Climate Change Adaptation in Cities (The World Bank, 2011)

26. G. Rossi, Drought mitigation measures: A comprehensive framework. In: Drought and drought mitigation in Europe, (Springer, 2000)

27. D.A. Wilhite, European Water, 34, 5-18 (2011)

28. G. Kallis, Annu Rev Env Resour, 33, 85-118 (2008)

Acknowledgements. The research was supported by the Ministry of Environment within the project Urban Adaptation Plans for cities with more than 100,000 inhabitants in Poland 